\title{
A Meta-Analysis of the Effects of Common Management Actions on the Nest Success of North American Birds
}

\author{
CYNTHIA HARTWAY* $†$ AND L. SCOTT MILLS* \\ *Wildlife Biology Program, Department of Ecosystem and Conservation Sciences, University of Montana, Missoula, MT 59812, U.S.A.
}

\begin{abstract}
Management strategies for the recovery of declining bird populations often must be made without sufficient data to predict the outcome of proposed actions or sufficient time and resources necessary to collect these data. We quantitatively reviewed studies of bird management in Canada and the United States to evaluate the relative efficacy of 4 common management interventions and to determine variables associated with their success. We compared bow livestock exclusion, prescribed burning, removal of predators, and removal of cowbirds (Molothrus ater) affect bird nest success and used meta-regression to evaluate the influence of species and study-specific covariates on management outcomes. On average, all 4 management interventions increased nest success. When common species and threatened, endangered, or declining species (as defined by long-term trend data from the North American Breeding Bird Survey) were analyzed together, predator removal was the most effective management option. The difference in mean nest success between treatment and control plots in predator-removal experiments was more than twice that of either livestock exclusion or prescribed burning. However, when we considered management outcomes from only threatened, endangered, or declining species, livestock exclusions resulted in the greatest mean increase in nest success, more than twice that of the 3 other treatments. Our meta-regression results indicated that between-species variation accounted for approximately 86\%, 40\%, 35\%, and 7\% of the overall variation in the results of livestock-exclusion, prescribed-burn, predator-removal, and cowbird-removal studies, respectively. However, the covariates we tested explained significant variation only in outcomes among prescribed-burn studies. The difference in nest success between burned and unburned plots displayed a significant, positive trend in association with time since fire and was significantly larger in grasslands than in woodlands. Our results bighlight the importance of comparative studies on management effects in developing efficient and effective conservation strategies.
\end{abstract}

Keywords: conservation planning, grazing, Molothrus, predator control, prescribed fire, restoration

Un Meta-Análisis de los Efectos de Acciones de Manejo Comunes Sobre el Éxito de Anidación de Aves de Norte América

Resumen: Las estrategias de manejo para la recuperación de poblaciones de aves en declinación a menudo deben definirse sin datos suficientes para predecir el resultado de las acciones propuestas o sin el tiempo suficiente ni los recursos necesarios para recolectar esos datos. Hicimos una revisión cuantitativa de estudios de manejo de aves en Canadá y los Estados Unidos para evaluar la eficacia relativa de 4 intervenciones de manejo comunes y para determinar variables asociadas a su éxito. Comparamos el efecto de la exclusión de ganado, la quema prescrita, la remoción de depredadores y la remoción de Molothrus ater sobre el éxito de anidación de aves y usamos meta-regresión para evaluar la influencia de especies y covariables específicas sobre los resultados del manejo. En promedio, las 4 intervenciones de manejo incrementaron el éxito de 
anidación. Cuando analizamos conjuntamente las especies comunes y las amenazadas, en peligro o en declinación (definida por tendencias en los datos de largo plazo del North American Breeding Bird Survey), la remoción de depredadores fue la opción de manejo más efectiva. La diferencia en el éxito de anidación promedio entre parcelas control y con tratamiento en experimentos de remoción de depredadores fue más del doble que con la exclusión de ganado o la quema prescrita. Sin embargo, cuando consideramos los resultados de manejo de especies amenazadas, en peligro o en declinación, la exclusión de ganado resultó en el mayor incremento en el éxito de anidación, más del doble que con los otros tres tratamientos. Nuestros resultados de meta-regresión indicaron que la variación entre especies explicó aproximadamente 86\%, 40\%, 35\% y 7\% de la variación total en los resultados de estudios con exclusión de ganado, quema prescrita, remoción de depredadores y remoción de Molothrus ater, respectivamente. Sin embargo, las covariables que probamos solo explicaron variación significativa en resultados entre estudios con quema prescrita. La diferencia en el éxito reproductivo entre parcelas quemadas y no quemadas mostró una tendencia significativa y positiva en asociación con el tiempo desde la quema y fue significativamente mayor en pastizales que en bosques. Nuestros resultados resaltan la importancia de los estudios comparativos de los efectos del manejo para el desarrollo de estrategias de conservación eficientes y efectivas.

Palabras Clave: control de depredadores, fuego prescrito, Molotbrus, pastoreo, planificación de la conservación, restauración

\section{Introduction}

A fundamental challenge in management of declining species is determining the most effective and efficient way to increase or stabilize the population growth rates of these species. For managers of populations of breeding birds, reducing nest predation rates is often a primary concern. Nest predation is the leading cause of nest mortality in birds (Martin 1995), and for bird species confined to ever-shrinking habitat fragments, high rates of nest predation and brood parasitism present immediate threats to long-term persistence (Heske et al. 2001; Ortega et al. 2005). Predator- and parasite-control programs are effective ways to increase the reproductive success of many bird populations (reviewed by Cote \& Sutherland 1997; Hall \& Rothstein 1999; Smith et al. 2010). Yet these programs can be costly and labor intensive, and in situations where the complete eradication of target predators is impossible or undesirable, such programs may need to be carried out in perpetuity to be of lasting benefit (Hall \& Rothstein 1999).

Although targeting predators has had positive effects on bird populations, the leading cause of bird declines around the world is the degradation and fragmentation of their habitat (Terborgh 1989; BirdLife International 2008). Changes in the structure and composition of plant communities that are characteristic of habitat degradation negatively affect birds by altering the availability of food resources and the suitability of nest sites, both of which may have direct negative effects on reproductive success and increase exposure to predators and brood parasites (Wiens 1973; Johnson \& Temple 1990; Saab et al. 1995). Reestablishing historic disturbance regimes through prescribed burning and the manipulation of grazing pressure are recognized as useful methods for improving habitat quality (Brawn et al. 2001; Askins 2002). Yet because birds have variable food and nest site re- quirements, the efficacy of these interventions depend on the specific ecological requirements of the target species.

How effective are measures aimed at improving habitat quality, such as livestock exclusion and prescribed burns, and parasite and predator control programs at reversing bird declines? What variables and conditions lend to their success or failure? A number of researchers have reviewed the effects of predator-removal programs on measures of bird abundance and reproductive success (e.g., Cote \& Sutherland 1997; Lavers et al. 2010; Smith et al. 2010), and, in most cases, they found large increases in values of these measures when predators are removed. In contrast, reviews on the effect of altered grazing and fire regimes on bird populations have focused exclusively on changes in abundance (Saab et al. 1995; Brawn et al. 2001; Saab \& Powell 2005; Kalies et al. 2010). These reviews demonstrate that prescribed burns and reductions in livestock grazing increase, decrease, or have no effect on abundance, depending on the foraging and nesting requirements of the target species. To date, reviews of the effects of brood-parasite control on their host populations have been qualitative (e.g., Hall \& Rothstein 1999; Ortega et al. 2005).

Results from reviews focusing solely on abundance measures could be misleading if bird abundance is uncorrelated (or negatively correlated) with the reproductive and survival rates that drive population trends. Habitats may appear to support stable or even increasing numbers of adult birds, but may in fact be ecological traps or sinks, with populations maintained only through immigration (e.g., Van Horne 1983; Brawn \& Robinson 1996; Weldon \& Haddad 2005). In a comprehensive review of the relation between bird density and reproductive success, Bock and Jones (2004) found that these measures were most likely to be negatively correlated in "human altered and disturbed" habitats. Populations occupying 
human-altered and disturbed habitats are often those most at risk and of most interest to managers. Thus to fully understand how effective management interventions are at bolstering bird populations, it is necessary to look at the demographic rates that determine abundance and trends (Martin 1995; Saab et al. 2005).

The most commonly studied and reported demographic rates for bird populations are measures related to reproductive success (Faaborg et al. 2010; Lavers et al. 2010), in particular nest survival or nest success. We used meta-analysis to analyze and compare the ability of 4 management interventions (livestock exclusion, prescribed burning, and predator and brood-parasite removal) commonly used in North America to increase avian reproductive success. Meta-analysis is a powerful method for synthesizing the results of multiple independent studies to determine the overall effect of some intervention (Gurevitch \& Hedges 1993). From each study, an effect size is calculated that quantifies the difference in mean response between treatment and control, standardized by some measure of the size and precision of that study (usually a function of the sample size and standard deviation). As a result, one can calculate the overall magnitude and direction of a treatment effect across studies and the contribution of various covariates to between-study variation in effect size. Researchers are increasingly using meta-analysis as a way to evaluate the success of conservation interventions (Sutherland et al. 2004; Pullin \& Knight 2009).

We compared the ability of livestock exclusion, prescribed burning, and predator and Brown-headed Cowbird (Molothrus ater) removal programs to increase bird nest success. We also tested how well species and studyspecific factors explain between-species variation in the outcomes of these management interventions. The factors we tested were foraging guild; nesting-layer guild; hatchling type; conservation status of target species; landcover type of study area; grazing intensity on control plots of livestock-exclusion studies; time since fire on burned plots in studies of prescribed burning; and measures of the spatial extent and relative effectiveness of predator or parasite removal.

\section{Methods}

\section{Literature Search and Data Extraction}

We searched the Web of Science, Agricola, WorldCat, and Dissertation Proquest International databases for relevant studies (see Table 1 for search terms). We also searched literature-cited sections of retrieved articles (e.g., Smith et al. 2010).

To make quantitative comparisons across study results, we required means and standard deviations of nest success from managed (treatment) and unmanaged (control) populations and sample sizes. Thus, to be included in our analyses, studies had to provide the information in text, tables, or figures that would allow us to calculate or estimate these statistics. We excluded studies in which multiple management interventions were applied together (e.g., managed plots both burned and grazed), studies that compared effects of different management interventions without reporting data for unmanaged populations (e.g., burned plots compared with grazed plots), studies that used artificial eggs, or studies focused solely on predator-exclosure methods or devices (as opposed to removals).

Many researchers reported data on the effect of a management intervention for multiple species. For these studies, we calculated effect sizes for each species separately because we were interested in the influence of species-specific characteristics (e.g., nesting-layer guild) on management outcomes (Borenstein et al. 2009). To account for this within-study data replication in our analyses, we used number of studies (as opposed to number of species) to calculate degrees of freedom and subsequent $p$ values.

Because the management interventions we analyzed were applied at the extent of sites, rather than to individual nests, we used site as our unit of analysis when calculating effect sizes for each species. Thus, sample sizes were the number of sites or years for which data were reported, and we used means and standard deviations calculated across sites or years to calculate effect sizes.

Table 1. Results of the literature search in the meta-analysis of management effects on the nest success of birds.

\begin{tabular}{|c|c|c|c|}
\hline Prescribed burns & $\begin{array}{l}\text { ([nest or breed* or reproduc*] and [success or survival or } \\
\left.\text { mort }^{*}\right] \text { ) and (fire* or burn*) and bird* }\end{array}$ & 178 & $19(52)$ \\
\hline Livestock exclusion & $\begin{array}{l}\left.\text { ([nest or breed* or reproduc }{ }^{*}\right] \text { and [success or survival or } \\
\left.\text { mort }^{*}\right] \text { ) and }\left(\text { graz }^{*}\right) \text { and bird }\end{array}$ & 157 & $16(35)$ \\
\hline Predator removal & $\begin{array}{l}\left.\text { ([nest or breed* or reproduc }{ }^{*}\right] \text { and [success or survival or } \\
\left.\left.\text { mort }^{*}\right]\right) \text { and (pred* and [removal or control]) and bird* }\end{array}$ & 508 & $17(22)$ \\
\hline
\end{tabular}


Researchers reported a variety of measures related to reproductive success. The most common was percent nest success (defined as the percentage of nests from which at least one bird fledged). To make across-study comparisons, we converted all reported measures related to reproductive success to percent nest success.

\section{Covariate Data}

We categorized the habitat in which studies were carried out as woodlands, grasslands, or shrublands. We categorized riparian areas as woodland and wetland areas as grasslands. Due to small sample sizes, we did not test whether predator removal (all but 3 studies conducted in grasslands) or cowbird removal (all but 1 study conducted in woodlands) varied as a function of habitat type.

We used information provided by study authors or from Birds of North America Online to categorize birds by nesting-layer guild, foraging guild, and hatchling type (Poole 2005). Nesting-layer guilds were ground, shrub, and canopy nesters. Due to the relatively low number of species that nest in tree holes (5), we categorized treehole nesting birds as canopy nesters. Foraging guilds were omnivore, ground insectivore, and aboveground foraging insectivore. The aboveground category combined aerial, foliage-gleaning, and bark-gleaning insectivore guilds because each of these guilds was sparsely represented in the studies. Hatchling type was altricial or precocial. We used foraging guild as a covariate only in analyses of prescribed burns and livestock exclusion. We did not use hatchling type or nesting-layer guild in our analysis of predator removal because most predator-removal studies (91\%) concerned precocial, ground-nesting birds.

We specified conservation status of species as either "of conservation concern" or "not of concern." Bird populations were classified as of conservation concern if they were identified as such by study authors (including use of descriptors such as "locally declining"); listed as threatened, endangered, or of special concern on Canada's Species at Risk Public Registry or by the U.S. Fish and Wildlife Service; or identified as declining significantly at a regional level by the trend estimator of the North American Breeding Bird Survey (Sauer et al. 2008).

For studies of livestock exclusion, we tested whether the intensity of grazing on the unmanaged (control) plots influenced the size of the effect between control and treatment plots. We classified grazing intensity as the mean number of animals grazing per hectare in control plots (most commonly reported statistic). For prescribed burns, we tested whether the number of years elapsed since burning (time since fire) affected effect size. We chose the maximum number of postfire years for which data were reported per study as our measure of time since fire.

For both predator and cowbird removals, we quantified the effectiveness of removals as the proportional difference in some index (PI) of either mean predator abundance (e.g., track counts, trapping, surveys) or mean parasitism rates between removal and nonremoval plots: 1 - (PI in removal plots/PI in nonremoval plots).

For predator removals, we also included the natural $\log$ of the mean area of treatment plots as a covariate. We excluded area of the treatment plot from analyses of cowbird removals because we had too few data on this covariate for this management category.

\section{Statistical Analyses}

We used Hedge's $d$ as our measure of effect size, which is the difference in mean nest success between managed plots $\left(\bar{x}_{T}\right)$ and unmanaged plots $\left(\bar{x}_{C}\right)$ standardized by an estimate of the study's precision and corrected for bias arising from small sample sizes (Hedges \& Olkin 1985):

$$
\begin{gathered}
d=\frac{\bar{x}_{T}-\bar{x}_{C}}{S_{p}} J, \\
S_{p}=\sqrt{\frac{\left(n_{T}-1\right) s_{T}^{2}+\left(n_{C}-1\right) s_{C}^{2}}{n_{T}+n_{C}-2}},
\end{gathered}
$$

and

$$
J=1-\frac{3}{4\left(n_{T}+n_{C}-2\right)-1}
$$

where $S_{p}$ is the pooled standard deviation, $J$ is a correction factor for small sample sizes, $n_{T}$ and $n_{C}$ are, respectively, sample sizes for the managed and unmanaged populations, and $s_{T}$ and $s_{C}$ are, respectively, the standard deviations of managed and unmanaged populations. The variance of $d$ is

$$
v=\frac{n_{C}+n_{T}}{n_{C} n_{T}}+\frac{d^{2}}{2\left(n_{C}+n_{T}\right)} .
$$

Hedge's $d$ is the difference between mean nest success in managed and unmanaged plots measured in units of standard deviations. Thus, a $d$ value of 1.8 indicates that, on average, nest success is $1.8 \mathrm{SDs}$ greater in managed plots than unmanaged plots. An effect size of $<0$ indicates nest success decreased as a function of management.

We first tested whether effect-size means differed between management interventions (livestock exclusion, prescribed burns, predator removal, and cowbird removal) for all bird species. We then tested whether species of conservation concern differed in their responses to these interventions. We conducted each analysis as a random-effects weighted analysis of variance (ANOVA). We used a random-effects model because we assumed there was real, unexplained variation in effect sizes among studies that could not be accounted for by our chosen grouping variables (Borenstein et al. 2009). We weighted effect sizes by the inverse of their variance (Eq. 4) (Hedges \& Olkin 1985). We carried out these analyses in Metawin 2.1 (Rosenberg et al. 2000). 


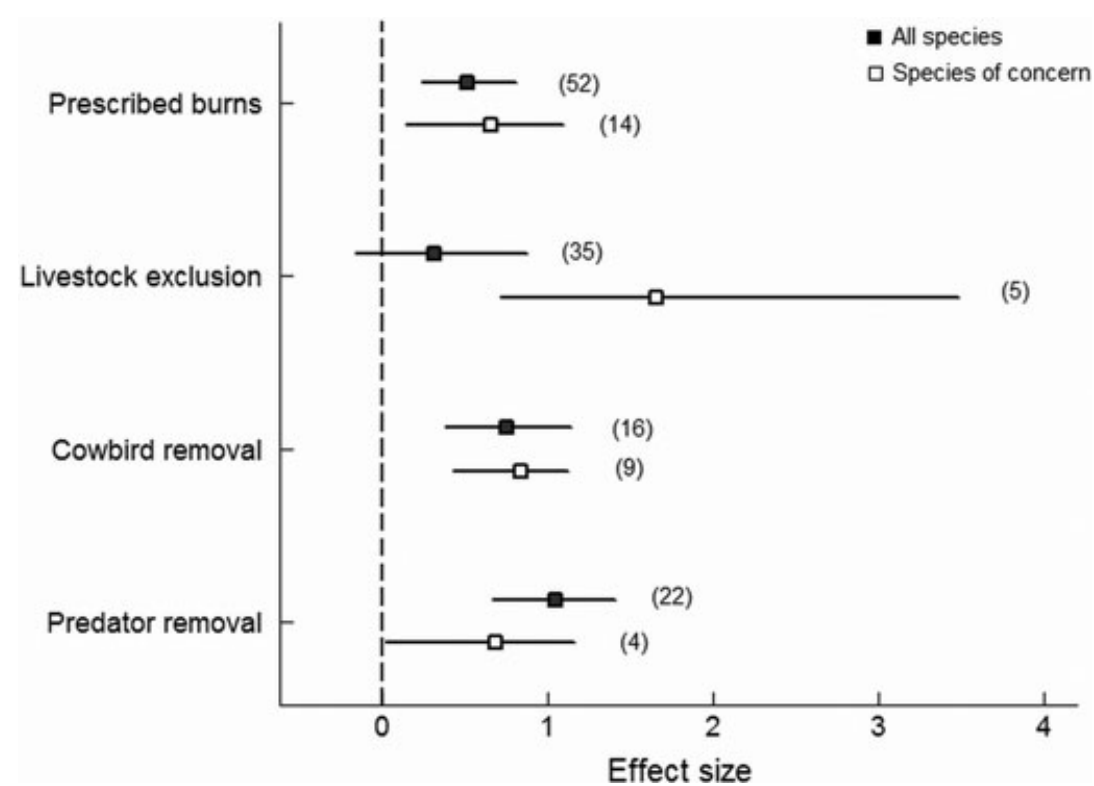

Figure 1. Mean effect of management interventions on nest success for all bird species for which studies were available and on only the subset of these species identified as being of conservation concern (e.g., species that have undergone substantial population declines) (parentheses, number of species; error bars, 95\% bootstrapped CIs). Effect size is the difference in nest success between managed and unmanaged plots, standardized by the size and precision of each study. Values $>0$ mean the management action increases nest success, whereas values $<O$ indicate the management action decreases nest success.
We used random-effects multiple regression to test the ability of our selected covariates to explain heterogeneity in effect size among species within each management category. This approach partitions the total variation across species' effect sizes into estimates of within-species variation and between-species variation and then estimates how well covariates explain the latter (Higgens et al. 2003). For each management intervention, we started with a model that included all covariates for which we had complete coverage across studies (see Supporting Information for data on covariates). To simplify these models, we used backwards stepwise selection to eliminate covariates with nonsignificant effects. We then separately tested the effect of covariates that were available only for a subset of studies, again simplifying models through backwards stepwise selection. We used the module Metareg in STATA (version 11, STATA Corporation, College Station, Texas) to perform multiple regressions (Sharp 1998).

\section{Results}

We found 1129 potentially relevant studies, of which 62 met the criteria for our analyses (Table 1 ). The primary reasons for exclusion of otherwise relevant studies were a lack of proper controls, insufficient information provided to estimate effect sizes, and studies conducted in only 1 site in 1 year (i.e., sample size of one control and one treatment). Effect sizes calculated for all species, covariate values, and citations are provided in online Supporting Information.

Nest success did not differ statistically among management strategies $(\phi=0.16)$ (Fig. 1). All interventions increased nest success on average, with predator and brood-parasite removal resulting in the greatest increases. Nest success was approximately 1.1 SDs greater in predator removal plots than in nonremoval plots, whereas cowbird removals, prescribed burns, and livestock exclusion resulted, respectively, in nest success increases approximately $0.76,0.52$, and 0.31 SDs greater than their respective controls. Results from livestock exclusion studies were the most variable; 95\% CIs included zero (i.e., no effect of treatment). In contrast, results from only the subset of species considered to be of conservation concern indicated livestock exclusion was associated with the largest increase in nest success, although again, the mean outcome among the 4 management interventions did not differ statistically $(\phi=0.31)$ (Fig. 1$)$. On average, nest success was approximately 1.7 SDs greater for these species when livestock were excluded, whereas prescribed burns, cowbird removal, and predator removals resulted in nest success increases $0.66,0.84$, and 0.69 SDs greater than their respective controls.

Our meta-regression results indicated that approximately $40 \%$ of the variation in effect size from studies of prescribed fires was due to differing responses of species to this management intervention. Habitat type, hatchling type, and number of years after fire for which data were collected all explained significant variation in effect size (Table 2). The standardized difference in nest success between burned and unburned plots $(d)$ increased by 0.23 with each year elapsed since burning (Table 2). When effects of all other covariates were controlled, the effect of burning on nest success was significantly greater for species in grasslands (mean $d=0.81$ ) than those in woodlands (mean $d=0.43$ ) (Fig. 2). The difference in nest success between burned and unburned plots was significantly lower for precocial species (mean $d=-0.17$ ) than for altricial species (mean $d=0.60$ ) (Table 2 ). 


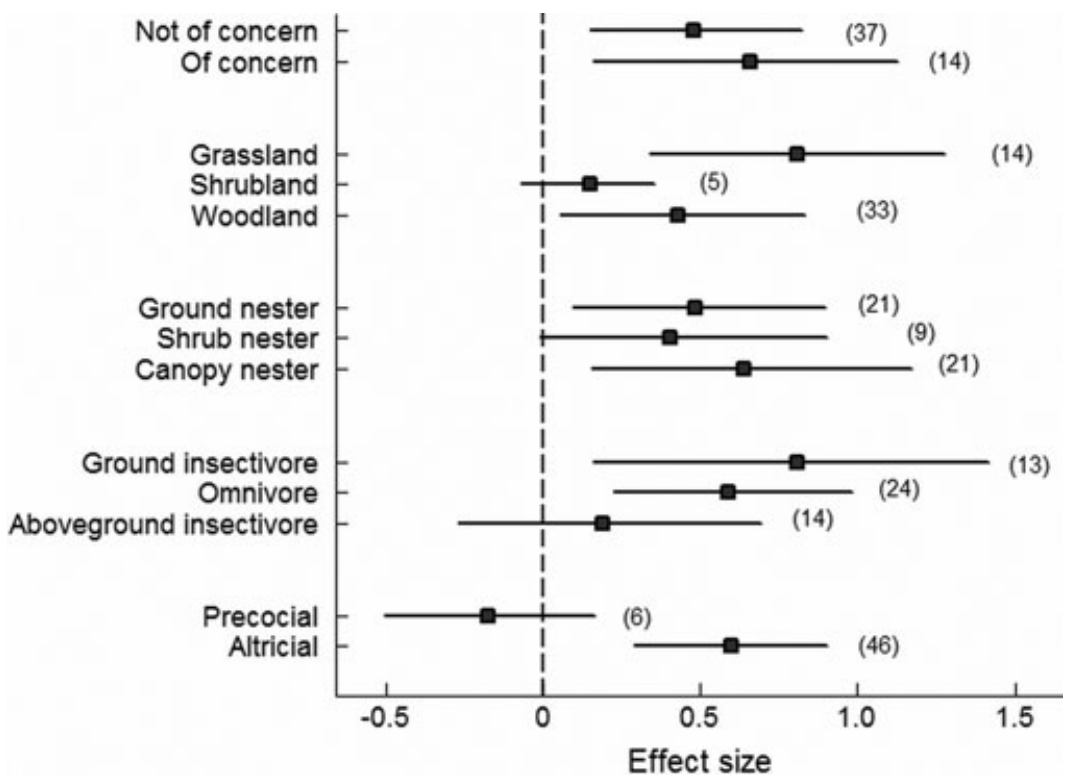

Figure 2. Effect of prescribed burning on the nest success of birds as a function of species and study-specific variables (species conservation status, habitat, nest location, foraging guild, hatchling type) (parentheses, number of species; error bars, 95\% bootstrapped CIs; effect size defined in legend of Fig. 1).

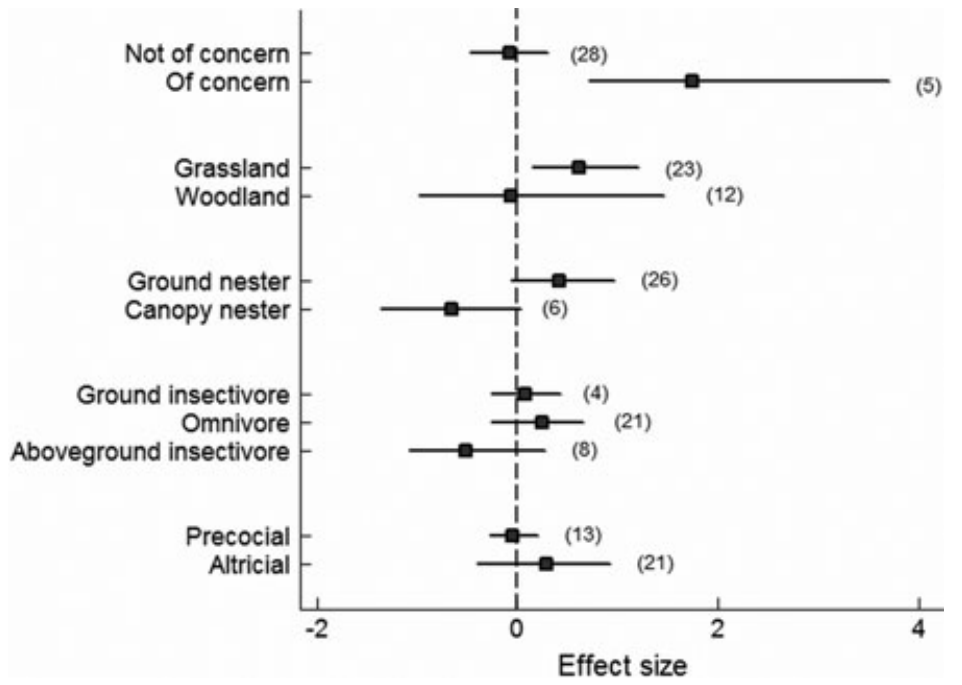

Figure 3. Effect of livestock exclusion on the nest success of birds as a function of species and study-specific variables (species conservation status, habitat, nest location, foraging guild, hatchling type) (parentheses, number of species; error bars, 95\% bootstrapped CIs; effect size defined in legend of Fig. 1).
Between-species variation accounted for approximately $86 \%$ of the variation in results from livestock exclusion studies (Fig. 3), 7\% of the variation in cowbirdremoval studies (Fig. 4), and 35\% of the variation in results from predator removal studies. However, none of the covariates tested were significantly associated with the outcome of these management interventions.

\section{Discussion}

On average all 4 management interventions increased the nest success of birds. When both common species and species of conservation concern were considered together, predator removal increased nest success the most; the average increase in nest success was almost

Table 2. Results of meta-regression models fit for between-species differences in the effect of prescribed burns on the nest success of birds.

\begin{tabular}{|c|c|c|c|c|c|}
\hline Treatment & Covariates $^{a}$ & Coefficient (SE) & $T$ & $p>|t|$ & $95 \% C I$ \\
\hline \multicolumn{6}{|c|}{ Prescribed burns } \\
\hline & woodland $^{b}$ & $-1.11(0.378)$ & -2.93 & 0.011 & -1.919 to -0.298 \\
\hline & altricial hatchling type ${ }^{c}$ & $-1.36(0.477)$ & -2.84 & 0.013 & -2.378 to -0.332 \\
\hline & years after fire & $0.232(0.082)$ & 2.84 & 0.013 & 0.057 to 0.408 \\
\hline & intercept only & $0.990(0.308)$ & 3.21 & 0.006 & 0.321 to 1.588 \\
\hline
\end{tabular}

${ }^{a}$ Only results from significant covariates are shown.

${ }^{b}$ Grassland is the reference category for woodland results.

${ }^{c}$ Precocial hatchling type is the reference category for altricial results. 
twice that of livestock exclusions and prescribed burns. However, when we considered the effects of these management interventions on only threatened, endangered, or declining species, livestock exclusion resulted in the largest average increase in nest success. Thus, for some species of concern in the United States and Canada, strategies aimed at improving habitat quality (e.g., excluding livestock) can be just as effective as, and possibly more effective, than predator and cowbird control.

Results of livestock exclusions were more variable than those of the other management interventions, and our results indicated the vast majority of this effect size heterogeneity (86\%) was due to differences in the responses of individual species to livestock exclusion. None of the covariates we tested were significantly associated with this variation. However, there was a large increase in nest success, on average, of species of conservation concern when livestock were excluded from nesting habitat. In contrast, for some of the more common species, nest success decreased when livestock were excluded.

Much of the unexplained variability in the response of birds to livestock exclusion may be related to the areas in which these studies took place. Half of all the grazingrelated studies were conducted in the Great Plains region of North America. Historically, this region was shaped by the wide-ranging, intensive grazing of large hoofed mammals (e.g., Bison bison) (Knapp et al. 1999). Many grassland bird species may require the heterogeneous landscapes resulting from such varying levels of grazing and regrowth of vegetation (e.g., Fuhlendorf \& Engle 2001; Coppedge et al. 2008). The covariates we tested may not capture the variables to which grassland birds are really responding, such as interactions between grazing intensity and vegetation density (Saab et al. 1995), or time elapsed between bouts of grazing (Knapp et al. 1999). In addition, many of our grazing studies took place in semiarid systems, where weather fluctuations can in-

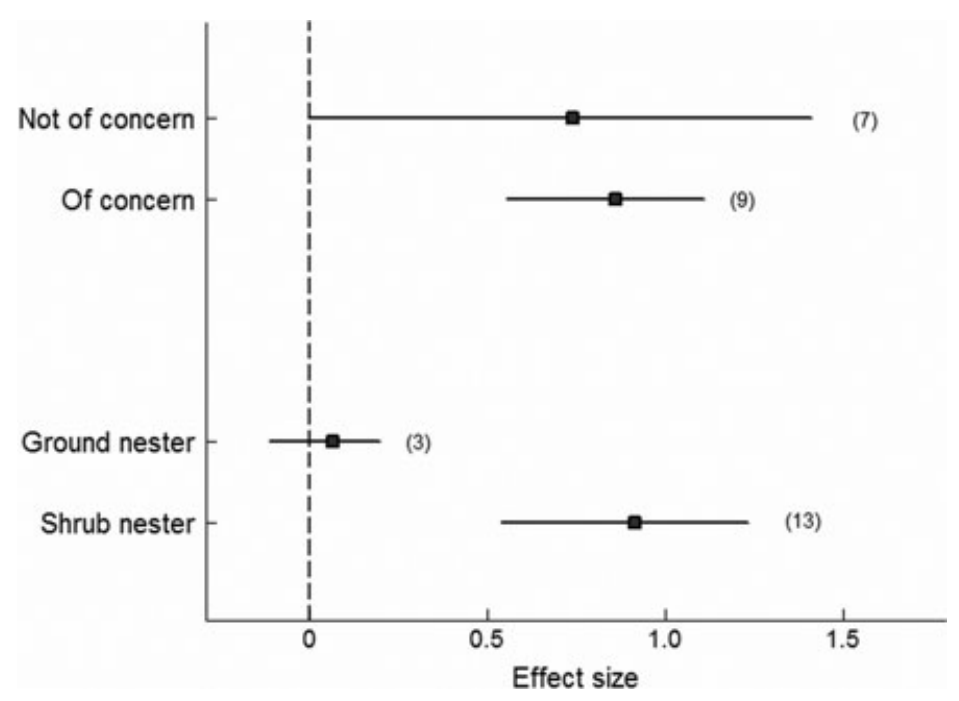

duce large changes in vegetation structure and community composition (Knapp \& Smith 2001). In some studies, variability in weather between years and sites may have interacted with or negated the effect of livestock exclusion on nest success (e.g., Rahmig et al. 2009).

Our results also suggest that canopy- and groundnesting birds differ in their response to the exclusion of livestock. On average, nest success of canopy-nesting birds was lower in sites from which livestock were excluded than in grazed sites. This result is likely due to the small number of canopy-nesting birds studied ( $n=$ 6) and the strong negative responses of 2 species from 1 study (Bushtits [Psaltriparus minimus] and Western Tanagers [Piranga ludoviciana]) (Goguen \& Mathews 1998), both of which are above-ground foraging insectivores. Goguen and Mathews (1998) suggest their results were driven by the lack of significant vegetation differences between their treatment and control plots and by high rates of cowbird parasitism in both. Grazing is typically hypothesized to have negative effects on the breeding success of woodland bird species (Fleischner 1994; Martin et al. 2005), which leads us to assume livestockexclusion sites will have higher nest success than grazed sites. Further investigations into the effects of grazing on the nest success of birds in forested landscapes, and as a function of nest height, are needed to determine the generality of these results.

Our results indicated that the difference in nest success between burned and unburned plots increased as a function of time since fire. This result is likely due to interactions among species, habitat, and study-specific factors. For example, most of the species responses we analyzed came from woodland and shrubland habitats (38 of 52 species) and involved relatively recent burns, typically with data for only 0-5 years after fire. For many woodland species nest success decreased on recently burned plots compared with controls. In contrast, nest
Figure 4. Effect of Brown-beaded Cowbird removal on the nest success of birds as a function of species-specific variables (species conservation status, nest location) (parentheses, number of species; error bars, 95\% bootstrapped CIs; effect size defined in legend of Fig. 1). 
success of 6 grassland birds increased substantially on burned plots relative to controls (e.g., Clay-colored Sparrow [Spizella pallida], Western Meadowlark [Sturnella neglecta]) when plots were burned at annual or nearannual intervals.

The individual characteristics of the woodland species studied may have driven the increases in nest success associated with increases in time since fire. For example, in a study of cavity-nesting birds, Saab et al. (2011) found that nest survival decreases as time since fire increases due to an increase in nest predation. In our study, some of the birds with the largest decreases in nest success on recently burned plots were ground-nesting species (e.g., Dark-eyed Junco [Junco byemalis], Ovenbird [Seiurus aurocapilla]). An immediate reduction in ground cover after a burn could increase nest mortality for such species.

Because we wanted to compare the effects of different management interventions on nest success, we excluded a number of studies that combined multiple management interventions (e.g., studies in which treatment plots were both burned and grazed). Our resulting, relatively small sample sizes precluded the analyses of some potentially important sources of among-study variation (such as season of burning or grazing) and possible interactions between covariates (e.g., nesting-layer guild and time since fire). Focused analyses of a particular management intervention could include a larger set of relevant studies and allow for the exploration of these potential treatment modifiers with greater statistical power.

We found, as did Cote and Sutherland (1997), Holt et al. (2008), and Smith et al. (2010), that predator removal greatly increased nest success, yet none of the covariates we tested explained significant variability in the responses of birds to removals. We found no statistical evidence for an association between indices of predator abundance and nest success in studies of predator removal. This result could be the consequence of low statistical power (only 10 studies reported indices [Supporting Information]). It could also mean that some of these indices are poor indicators of actual predation rates or do not represent the wider community of predators. Large reductions (or even eradication) of targeted predators can result in weak reductions in overall predation rates if there are compensatory responses from remaining predators (e.g., Dion et al. 1999).

To have sufficient data to make comparisons across management interventions, we focused our analyses on nest success. As such, we ran the risk of underestimating the true effects of cowbird removal, the main effect of which should be on host recruitment rates. However, we found that cowbird removal resulted in nest success approximately 0.76 SDs higher than in nonremoval sites, which lends support to the idea that in addition to reducing parasitism rates, cowbird control also decreases overall abandonment of nests and nest predation (Zanette et al. 2007).

Correlations between habitat degradation and increased parasitism rates by cowbirds across North America (Ortega et al. 2005) have led to considerable debate about the relative merits of habitat-restoration measures versus measures to control cowbirds for the conservation of birds susceptible to cowbird parasitism (e.g., Rothstein \& Peer 2005). Although our results indicate greater increases in nest success for species of concern when livestock are removed than when cowbirds are removed, the relatively small number of studies documenting the effects of either management on species of concern does not allow us to make a robust comparison of their relative efficacy. Likewise, although the existing literature on the effects of cowbird parasitism on their hosts is extensive (e.g., Lorenzana \& Sealy 1999), our literature search indicated that studies documenting the actual effect of cowbird management on host demographic rates are relatively rare.

For birds nest success is the most widely studied and reported demographic rate (Faaborg et al. 2010). However, the ultimate effect of nest success on population growth of any species depends on that species' individual life history (Saether \& Bakke 2000). The importance of collecting more comprehensive demographic data (reproduction and survival rates) in association with manipulativemanagement studies is widely recognized (e.g., Sherry \& Holmes 1995; Donovan et al. 2002; Fletcher et al. 2006). Although economically important species (such as waterfowl) have been studied extensively, studies of management effects on passarine demographic rates remain relatively rare (Faaborg et al. 2010).

We believe further research relating the effects of management on demographic rates across multiple species is essential to developing efficient and effective conservation strategies. Although the results of any one study may not be statistically significant, the cumulative evidence of multiple studies would allow one to better predict the outcome of management efforts and to identify factors that modify the success or failure of these actions (Gurevitch \& Hedges 1993; Sutherland et al. 2004). In the long run, the ability to formulate such guidelines should save time and money that might otherwise be wasted in repeated attempts at management on a trial-and-error, species-by-species basis.

\section{Acknowledgments}

We thank N. Harris and N. Korfanta for help with the literature search, M. Kauffman for useful discussions about the material, and the authors who shared their data. We are also grateful to J. Faaborg, D. Johnson, and an anonymous reviewer for valuable comments on the manuscript. This research was funded by SERDP (SI-1477 to L.S.M.). 


\section{Supporting Information}

Tables of covariate data (Appendix S1) and effect sizes and citations from all studies (Appendix S2) used in our meta-analysis are available online. The authors are solely responsible for the content and functionality of these materials. Queries (other than absence of the material) should be directed to the corresponding author.

\section{Literature Cited}

Askins, R. A. 2002. Restoring North America's birds: lessons from landscape ecology. Yale University Press, New Haven, Connecticut.

BirdLife International. 2008. State of the world's birds: indicators for our changing world. Birdlife International, Cambridge, United Kingdom.

Bock, C. E., and Z. F. Jones. 2004. Avian habitat evaluation: Should counting birds count? Frontiers in Ecology and Evolution 2:403410.

Borenstein, M., L. V. Hedges, J. P. T. Higgens, and H. R. Rothstein. 2009. Introduction to Meta-analysis. John Wiley and Sons, Chichester, United Kingdom.

Brawn, J. D., and S. K. Robinson. 1996. Source-sink population dynamics may complicate the interpretation of long term census data. Ecology 77:3-12.

Brawn, J. D., S. K. Robinson, and F. R. Thompson III. 2001. The role of disturbance on the ecology and conservation of birds. Annual Review of Ecology and Systematics 32:251-276.

Coppedge, B. R., S. D. Fuhlendorf, W. C. Harrell, and D. M. Engle. 2008. Avian community response to vegetation and structural features in grasslands managed with fire and grazing. Biological Conservation 141:1196-1203.

Cote, I. M., and W. J. Sutherland. 1997. The effectiveness of removing predators to protect bird populations. Conservation Biology 11:395-405.

Dion, N., K. A. Hobson, and S. Larviere. 1999. Effects of removing ducknest predators on nesting success of grassland songbirds. Canadian Journal of Zoology 77:1801-1806.

Donovan, T. M., et al. 2002. Priority research needs for the conservation of Neotropical migrant landbirds. Journal of Field Ornithology 73:329-339.

Faaborg, J., et al. 2010. Conserving migratory land birds in the New World: Do we know enough? Ecological Applications 20:398-418.

Fleischner, T. L. 1994. Ecological costs of livestock grazing in western North America. Conservation Biology 8:629-644.

Fletcher, R. J., R. R. Koford, and D. A. Seaman. 2006. Critical demographic parameters for declining songbirds in restored grasslands. Journal of Wildlife Management 70:145-157.

Fuhlendorf, S. D., and D. M. Engle. 2001. Restoring heterogeneity on rangelands: ecosystem management based on evolutionary grazing patterns. BioScience 51:625-632.

Goguen, C. B., and N. E. Mathews. 1998. Songbird community composition and nesting success in grazed and ungrazed Pinyon-Juniper woodlands. Journal of Wildlife Management 62:474-484.

Gurevitch, J., and L. V. Hedges. 1993. Meta-analysis: combining the results of independent studies in experimental ecology. Pages 378-398 in S. Scheiner and J. Gurevitch, editors. The design and analysis of ecological experiments. Chapman and Hall, New York.

Hall, L. S., and S. I. Rothstein. 1999. Cowbird control: the efficacy of long-term control and proposed alternatives to standard control practices. Studies in Avian Biology 18:254-259.

Hedges, L. V., and I. Olkin. 1985. Statistical methods for meta-analysis. Academic Press, Orlando, Florida.

Heske, E. J., S. K. Robinson, and J. D. Brawn. 2001. Nest predation and Neotropical migrant songbirds: piecing together the fragments. Wildlife Society Bulletin 29:52-61.
Higgens, J., S. G. Thompson, J. J. Deeks, and D. G. Altman. 2003. Measuring inconsistency in meta-analysis. British Medical Journal 327:557-560.

Holt, A. R., Z. G. Davies, C. Tyler, and S. Staddon. 2008. Metaanalysis of the effects of predation on animal prey abundance: evidence from UK vertebrates. Public Library of Science ONE 3 DOI:10.1371/journal.pone.0002400.

Johnson, R. G., and S. A. Temple. 1990. Nest predation and brood parasitism of tallgrass prairie birds. Journal of Wildlife Management 54:106-111.

Kalies, E. L., C. L. Chambers, and W. W. Covington. 2010. Wildlife responses to thinning and burning treatments in southwestern conifer forests: a meta-analysis. Forest Ecology and Management 259:333-342.

Knapp, A. K., and M. D. Smith. 2001. Variation among biomes in temporal dynamics of above-ground primary productivity. Science 291:481-484.

Knapp, A. K., J. M. Blair, J. M. Briggs, S. L. Collins, D. C. Hartnett, L. C. Johnson, and E. G. Towne. 1999. The keystone role of bison in North American tallgrass prairie. BioScience 49:39-50.

Lavers, J. L., C. Wilcox, and C. J. Donlan. 2010. Bird demographic responses to predator removal programs. Biological Invasions 12:3839-3859.

Lorenzana, J.C., and S. G. Sealy. 1999. A meta-analysis of the impact of parasitism by the brown-headed cowbird on its hosts. Studies in Avian Biology 18:241-253.

Martin, T. E. 1995. Avian life history evolution in relation to nest sites, nest predation and food limitation. Ecological Monographs 65:101-127.

Martin, T. G., P. M. Kuhnert, K. Mengersen, and H. P. Possingham. 2005. The power of expert opinion in ecological models using Bayesian methods: impact of grazing on birds. Ecological Applications 15:266-280.

Ortega, C. P., J. F. Chace, and B. D. Peer. 2005. Research directions and cowbird (Molothrus spp.) management. Ornithological Monographs 57:1-5.

Poole, A., editor. 2005. The birds of North America online. Cornell Laboratory of Ornithology, Ithaca, New York. Available from http://bna.birds.cornell.edu/BNA/ (accessed January 2011).

Pullin, A. S., and T. M. Knight. 2009. Doing more harm than goodbuilding an evidence-base for conservation and environmental management. Biological Conservation 142:931-934.

Rahmig, C. J., W. E. Jensen, and K. A. With. 2009. Grassland bird responses to land management in the largest remaining tallgrass prairie. Conservation Biology 23:420-432.

Rosenberg M. S., D. C. Adams, and J. Gurevitch. 2000. MetaWin: statistical software for meta-analysis, version 2. Sinauer, Sunderland, Massachusetts.

Rothstein, S. I., and B. D. Peer. 2005. Conservation solutions for threatened and endangered cowbird (Molothrus spp.) hosts: separating fact from fiction. Ornithological Monographs 57:98114.

Saab, V. A., C. E. Bock, T. D. Rich, and D. S. Dobkin. 1995. Livestock grazing effects in western North America. Pages 311-353 in T. E. Martin and D. M. Finch, editors. Ecology and management of Neotropical migratory birds. Oxford University Press, New York.

Saab, V. A., R. E. Russell, J. Rotella, and J. G. Dudly. 2011. Modeling nest survival of cavity-nesting birds in relation to postfire salvage logging. Journal of Wildlife Management 75:794-804.

Saab, V. A., and H. D. W. Powell. 2005. Fire and avian ecology in North America: process influencing pattern. Studies in Avian Biology 30:1-13.

Saether B. E., and O. Bakke. 2000. Avian life history characteristics and contributions of demographic traits to the population growth rate. Ecology 81:642-653.

Sauer, J. R., J. E. Hines, and J. Fallon. 2008. The North American breeding bird survey, results and analysis 1966 - 2007, version 2008. 
U.S. Geological Survey Patuxent Wildlife Research Center, Laurel, Maryland.

Sharp, S. 1998. Meta-analysis regression: statistics, biostatistics and epidemiology. Stata Technical Bulletin 42:16-22.

Sherry, T. W., and R.T. Holmes. 1995. Summer versus winter limitation of populations: What are the issues and what is the evidence? Pages 85-120 in T. E. Martin and D. M. Finch, editors. Ecology and management of Neotropical migratory birds. Oxford University Press, New York.

Smith, R. K., A. S. Pullin, G. B. Gavin, and W. J. Sutherland. 2010. Effectiveness of predator removal for enhancing bird populations. Conservation Biology 24:820-829.

Sutherland W. J., A. S. Pullin, P. M. Dolman, and T. M. Knight. 2004.
The need for evidence-based conservation. Trends in Ecology \& Evolution 19:305-308.

Terborgh, J. 1989. Where have all the birds gone? Princeton University Press, Princeton, New Jersey.

Van Horne, B. 1983. Density as a misleading indicator of habitat quality. Journal of Wildlife Management 47:893-901.

Weldon, A. J., and N. M. Haddad. 2005. The effects of patch shape on indigo buntings: evidence for an ecological trap. Ecology 86:1422-1431.

Wiens, J. A. 1973. Pattern and process in grassland bird communities. Ecological Monographs 43:237-270.

Zanette, L., D. T. Haydon, J. N. M. Smith, M. J. Taitt, and M. Clinchy. 2007. Reassessing the Cowbird threat. Auk 124:210-223.

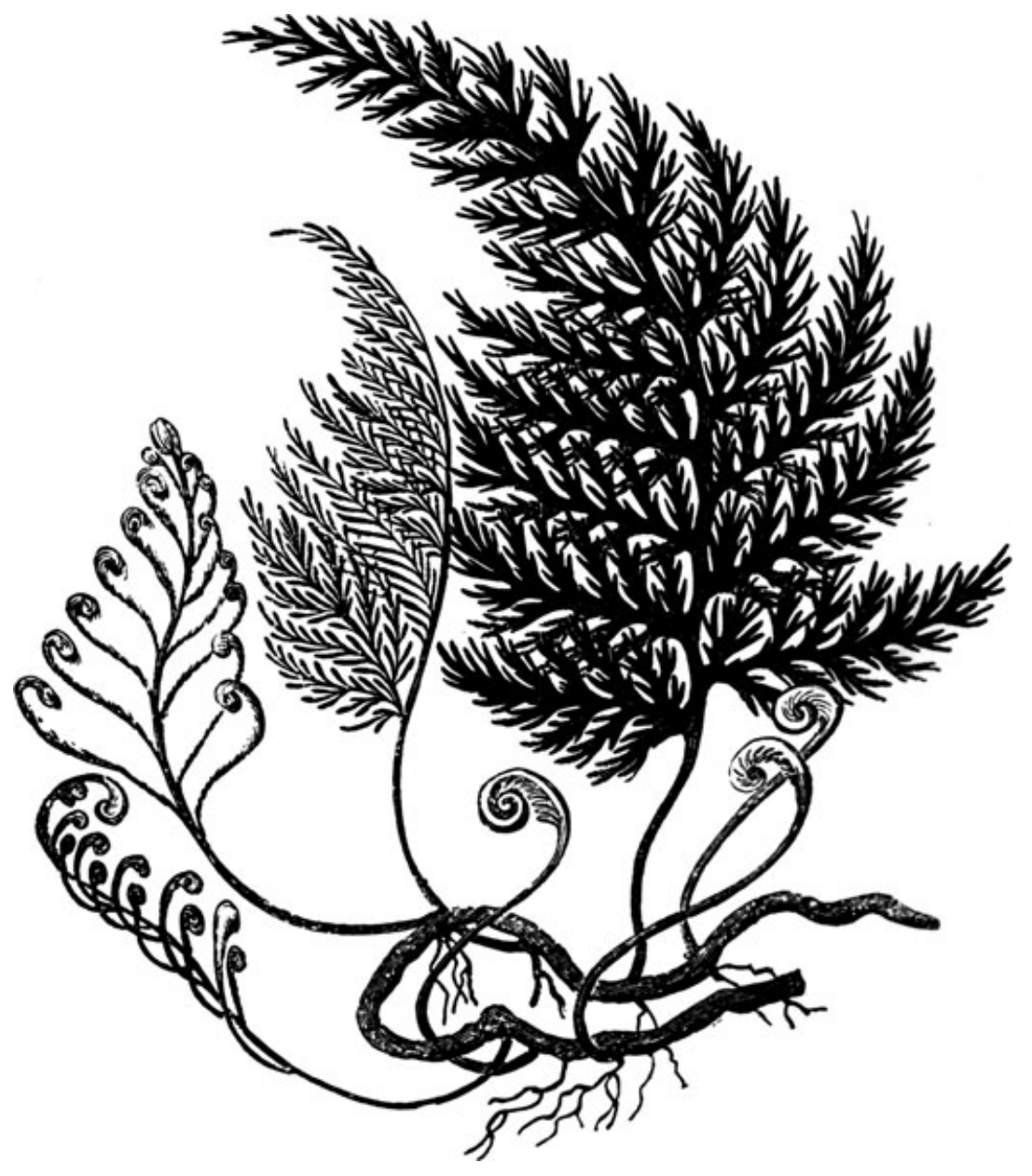

